\title{
KESAN RAWATAN MELALUI SUNTIKAN KE ATAS PUASA PESAKIT
}

\section{The Effects of Treatment by Injection on \\ Fasting Patients}

\author{
Hamidah Mat * \\ Anisah Ab Ghani*
}

\begin{abstract}
This article aims to discuss the effects of treatment by injection on the rule of fasting. Previously, the issue of treatment has been the subject of debate among the fuqaha in assessing the impact of treatment on the ruling of fasting patients. This is because the medical treatment, which involves the insertion of something into acavity of the body has been considered nullified by the majority of fuqaha in the past. Also discussed are the basic principles underlying the assessment that can be applied to the assessment of the impact of other treatment methods on the ruling of fasting patients. This article is based on both library and field research. The library research focuses on collecting and analysing all the related information from both fiqh and the medical point of view. While the field research involved interviews with medical officers. This article found that treatments by injection are not considered as nullifiers of fasting except for the injections of food or drink in to the body.
\end{abstract}

Keywords: Fasting, Medical Treatment, Injection

* Calon Ijazah Doktor Falsafah (PhD), Jabatan Fiqh dan Usul, Akademi Pengajian Islam, Universiti Malaya, u_sumayyah@yahoo.com.

** Konsultan, Jabatan Fiqh dan Usul, Akademi Pengajian Islam, Universiti Malaya, anisah_apium@um.edu.my. 


\section{PENDAHULUAN}

Puasa yang merupakan rukun Islam kedua merupakan antara ibadah asas dalam Islam. Kepentingan ibadah puasa terserlah dengan keunggulan objektif utamanya sebagaimana yang telah dinyatakan dalam firman Allah SWT, iaitu:

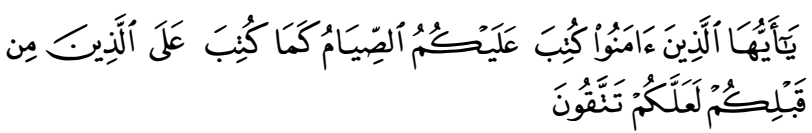

Maksudnya: Hai orang-orang yang beriman, diwajibkan atas kamu berpuasa sebagaimana diwajibkan atas orang-orang sebelum kamu agar kamu bertakwa.

Surah al-Baqarah (2): 183

Dalam ayat ini, Allah SWT menjelaskan bahawa objektif utama bagi puasa ialah penjanaan taqwa dalam diri seorang muslim. ${ }^{1}$ Taqwa yang dipupuk melalui ibadah puasa merupakan elemen penting bagi seseorang muslim menjaga hubungannya dengan Allah SWT demi menjaga agama dalam dirinya. Oleh itu, puasa merupakan wasilah penting untuk menjaga agama sebagaimana yang digagaskan di dalam maqāșid sharī'ah itu sendiri.

Antara gagasan maqāṣid sharī'ah juga ialah menjaga nyawa. Oleh itu, Islam menitikberatkan kelangsungan hidup manusia yang sihat dan sejahtera. Untuk itu, Islam telah mengiktiraf dua metod utama dalam penjagaan kesihatan iaitu kaedah pencegahan dan rawatan. Justeru, kedua-dua aspek ibadah dan penjagaan kesihatan haruslah dilihat sebagai pelengkap kepada kehidupan manusia yang sejahtera. ${ }^{2}$

1 Abū 'Abd Allāh Muḥammad bin Aḥmad al-Anșārī al-Qurțubī, alJāmi ' li Ahkām al-Qur'ān (Bayrūt: Dār Iḥyā' al-Turāth al-'Arabī, 1995), 1:275.

2 Husayn Ḥāmid Ḥasan, Nażariyyah al-Mașlaḥah fì al-Fiqh al-Islāmī (al-Qāhirah: Maktabah al-Mutanabbī, 1981), 28. 
Terdapat beberapa tanggapan bahawa sesetengah kaedah rawatan yang dijalankan pada hari ini membatalkan puasa pesakit atau orang yang menjalani rawatan. Hal ini berpunca daripada keterbatasan dalil-dalil yang menjelaskan tentang perkara-perkara yang membatalkan puasa. Berdasarkan dalil-dalil yang terbatas tersebut, fuqaha silam telah bersepakat ke atas tiga perkara yang membatalkan puasa iaitu makan dan minum, jimak dan memasukkan sesuatu ke dalam al-jawf. ${ }^{3}$ Walau bagaimanapun, para fuqaha berselisih pendapat mengenai hakikat dan perincian mengenai al-jawf itu sendiri. Keterbatasan dalil-dalil ini telah menatijahkan pandangan fuqaha mengenai hakikat al-jawf adalah bersifat ijtihad semata-mata. Keadaan ini bukanlah satu kekurangan yang mencacatkan usaha para fuqaha, tetapi merupakan cabaran bagi fuqaha dan pengkaji selepas itu untuk mengenalpasti apakah hakikat al-jawf yang menjadi pokok perbincangan perkara-perkara yang membatalkan puasa. Ini kerana pengertian al-jawf perlu diperhalusi untuk dijadikan asas kepada penilaian kaedah-kaedah rawatan perubatan yang sebahagian besarnya melibatkan perbuatan atau proses memasukkan sesuatu ke dalam badan. Justeru tulisan ini akan cuba menghuraikan kesan kaedah rawatan yang berbentuk suntikan kepada hukum puasa pesakit. Tulisan ini turut merujuk kepada pandangan sains perubatan dalam usaha memahami kaedah suntikan yang dilakukan, seterusnya mengemukakan pandangan fuqaha dalam menilai kesannya kepada hukum puasa.

\section{PRINSIP-PRINSIPASAS DALAM PENILAIAN PERKARA- PERKARA YANG MEMBATALKAN PUASA}

Isu-isu rawatan dan perubatan dalam konteks perkara-perkara yang membatalkan puasa telah diperbincangkan oleh fuqaha silam, namun ianya berlaku dalam bentuk yang ringkas. Hal ini merujuk kepada realiti dunia rawatan dan perubatan pada zaman silam yang berlaku dalam bentuk yang tidak formal dan lebih berbentuk rutin dan pengalaman hidup seharian. Tambahan pula, dalil-dalil khusus yang membincangkan tentang perkara-perkara yang membatalkan puasa adalah terhad. Oleh itu, untuk menilai

Abū Zakariyyā Mahy al-Dīn bin Sharaf al-Nawawī, Kitāb al-Majmū Sharh al-Muhadhdhab li al-Shīrāzì (Bayrūt: Dār Iḥyā' al-Turāth al'Arabī, 1995), 6:334. 
kesan kaedah-kaedah rawatan terhadap puasa pesakit, beberapa prinsip perlu diambilkira agar pandangan yang diberikan akan menepati kehendak syarak. Antara prinsip tersebut:

1. Memahami maqāṣid puasa dalam kerangka Maqāṣid alSharī'ah.

Antara objektif utama ibadah puasa ialah penjanaan taqwa dalam diri seseorang muslim, ${ }^{4}$ sebagaimana yang terkandung di dalam firman Allah SWT iaitu:

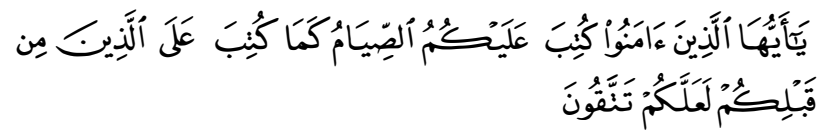

Maksudnya: Hai orang-orang yang beriman, diwajibkan atas kamu berpuasa sebagaimana diwajibkan atas orang-orang sebelum kamu agar kamu bertakwa.

Surah al-Baqarah (2): 183

Dalam ayat ini, kewajipan ibadah puasa ditegaskan oleh Allah SWT dengan perkataan كتبَ. Menurut ulama uṣūl alfiqh, lafaz ini merupakan lafaz yańg paling kuat menunjukkan tahap kewajipannya. ${ }^{5}$ Dalam ayat yang sama Allah SWT telah menyatakan bahawa natijah kepada puasa iaitu taqwa dengan menggunakan perkataan لَّلَ Dalam Bahasa Arab, perkataan لعَل menggambarkan sesuatu harapan yang sering dan berkemungkinan tercapai. ${ }^{6}$ Malah dalam mentafsirkan ayat ini, al-Rāzī menyifatkan puasa sebagai pewaris ketaqwaan kepada Allah SWT. Justeru, semantik ayat ini bukan sahaja menunjukkan tahap kewajipan berpuasa, malah pada masa yang sama memberikan jaminan bahawa taqwa akan tercapai dengan berpuasa. Melalui ibadah puasa, taqwa dipupuk dengan

$4 \quad$ Fatḥ̄ al-Duraynī, Dirāsāt wa Buḥūth fì al-Fikr al-Islāmī al-Mu 'āṣir (Damshiq: Dār Qutaybah, 1998), 3:580.

5 Wahbah al-Zuhaylī, Ușūl al-Fiqh al-Islāmī (Bayrūt: Dār al-Fikr alMu'āșir, 1986), 1:219.

6 Ibrāhīm Anīs et al., al-Mu jam al-Wasìt (al-Qāhirah: t. p., 1392), 828. 
perbuatan meninggalkan makan, minum dan nafsu syahwat semata-mata kerana Allah SWT. Ini merupakan latihan kepada seorang muslim untuk meninggalkan larangan Allah SWT walaupun pada hakikatnya ia adalah sesuatu yang selari dengan naluri kemanusiaannya. ${ }^{7}$

Pentafsiran kepada pengertian taqwa yang terkandung dalam al-Quran menyerlahkan lagi keistimewaan ibadah puasa. Penelitian terhadap ayat-ayat al-Quran mendapati bahawa di dalam al-Quran sering digandingkan dengan التقوى iaitu kebaikan dan kebajikan. ${ }^{8}$ Gandingan ini menunjukkan bahawa intipati dan tuntutan taqwa dan البر adalah seiring. ${ }^{9}$ Maksud taqwa telah diperjelaskan di dalam ayat البر iaitu:

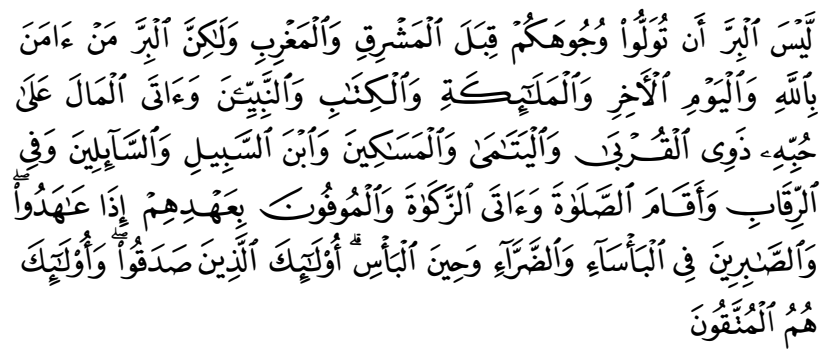

Maksudnya: Bukanlah menghadapkan wajahmu ke arah timur dan barat itu suatu kebajikan, akan tetapi, sesungguhnya kebajikan itu ialah beriman kepada Allah, Hari Kemudian, Malaikat-malaikat, Kitab-kitab, Nabi-nabi dan memberikan harta yang dicintainya kepada kerabatnya, anak-anak yatim, orang-orang miskin, musafir (yang memerlukan pertolongan) dan orang-orang yang meminta-minta;

$7 \quad$ Fakhr al-Dīn Muhammad bin 'Umar bin al-Husayn bin al-Hasan bin 'Alī al-Tamīmī al-Bakrī al-Rāzī, al-Tafsìr al-Kabīr (Bayrūt: Dār alKutub al-'Ilmiyyah, 1990), 5:59.

8 Dalam al-Quran, perkataan al-birr disebut sebanyak lapan kali, tujuh daripadanya digandingkan bersama perkataan al-taqwā. Contohnya sebagaimana yang terdapat dalam ayat-ayat berikut: Surah al-Baqarah (2): 177 dan 189, Surah Āli 'Imrān (3): 92, Surah al-Mā’idah (5): 2, Surah al-Mujādalah (58): 9. Lihat: http://qurancomplex.com, diakses pada 11 Februari 2012.

9 Al-Duraynī, Dirāsāt wa Buhūth, 3:586. 
dan (memerdekakan) hamba sahaya, mendirikan shalat, dan menunaikan zakat; dan orang-orangyang menepati janjinya apabila ia berjanji, dan orangorang yang sabar dalam kesempitan, penderitaan dan dalam peperangan. mereka Itulah orang-orang yang benar (imannya); dan mereka itulah orangorang yang bertakwa.

Ayat ini telah menghuraikan tentang isi kandungan البر yang menyentuh tatacara hubungan manusia dengan Tuhannya dan tatacara hubungan manusia sesama manusia. Melalui ayat ini dapat difahami bahawa البر merangkumi kebaikan secara menyeluruh dan merangkumi keseluruhan aspek kehidupan manusia. Penutup ayat ini mengaitkan antara التقوى dan apabila Allah SWT menyifatkan orang yang melakukan anjuran ayat ini sebagai orang yang bertaqwa. Ini menguatkan lagi bahawa makna dan tuntutan البر dadalah seiring dan saling melengkapi. ${ }^{10}$ Dengan itu, objektif puasa yang digambarkan sebagai taqwa bukan hanya terbatas kepada aspek spiritual (hubungan hamba dengan Tuhannya) sematamata malah menjangkau kepada aspek fizikal yang boleh dilihat dan dirasai oleh manusia. Ini termasuklah faedah-faedah kesihatan yang dijana oleh orang yang berpuasa. Bertitik tolak dari keistimewaan ibadah puasa yang telah disyariatkan inilah, setiap aspek pelaksanaan ibadah tersebut merupakan sesuatu yang perlu diberikan perhatian sewajarnya. Atas alasan yang sama, penilaian kesan kaedah rawatan ke atas puasa pesakit tidak boleh dilihat dari aspek fiqh semata-mata tetapi kesan ini perlu dipertimbangkan dengan mengambilkira falsafah puasa itu sendiri yang menitikberatkan pencapaian mașlahah terutamanya yang berkaitan kualiti kesihatan dan kesejahteraan manusia di dunia dan ketinggian mutu spiritualnya di Akhirat.

Sehubungan dengan itu, kajian-kajian mengenai puasa didapati membanjiri khazanah fiqh silam mahupun kontemporari. Kajian dan perbahasan fuqaha silam didapati tertumpu kepada hukum-hukum berkaitan puasa termasuklah

10 Al-Duraynī, Dirāsāt wa Buḥūth, 3:591. 
cara-cara dan syarat-syarat pelaksanaannya. Kajian-kajian fuqaha kontemporari pula didapati meluaskan lagi ufuk perbincangan mengenai ibadah puasa apabila puasa tidak dilihat melalui perpektif fiqh semata-mata tetapi dinilai berpaksikan maqāșid sharī'ah yang menaungi pensyariatan hukum-hukum Islam secara umumnya. Kajian-kajian yang dimaksudkan ialah seperti kajian-kajian yang menghubungkaitkan puasa dan kesihatan, perubatan, akhlak serta ekonomi.

Sebagai contoh, satu resolusi dari sebuah seminar antarabangsa yang telah diadakan di Casablanca pada tahun 1996 telah menyatakan bahawa ibadah puasa memberikan impak positif kepada tahap kesihatan terutamanya paras glukosa, tekanan darah, keseimbangan lipid di dalam badan dan berat badan yang ideal. ${ }^{11}$ Puasa juga dapat mengekalkan tahap kesihatan yang optimum dengan penyingkiran toksin dari badan. Toksin ialah bahan merbahaya yang masuk ke dalam badan melalui pemakanan dan udara yang kotor. Di dalam badan manusia, hati berfungsi untuk mengeluarkan toksin. Namun toksin yang berlebihan mungkin akan termendap di bawah tisu lemak dan akan kekal di dalam badan seterusnya akan menyebabkan kepada timbulnya penyakit. ${ }^{12}$ Puasa telah terbukti secara saintifik boleh membantu hati mengeluarkan toksin tersebut kerana ketika berpuasa, sejumlah besar lemak akan dipindah ke hati untuk dioksidakan dan dimanfaatkan. Oleh itu, toksin yang termendap di dalam lemak tersebut akan turut dilarutkan dan dikeluarkan dari badan melalui sistem perkumuhan. ${ }^{13}$ Oleh kerana lemak banyak digunakan semasa berpuasa, maka puasa merupakan rawatan berkesan kepada masalah obesiti atau kegemukan. Sebuah kajian telah dijalankan di sebuah universiti di Jordan yang melibatkan 70 pelajar dari tiga buah universiti yang berlainan telah menunjukkan

11 http://www.islam-usa.com/.

12 Agus Mustafa, Puasa Terapi dalam Ibadah (Batu Caves: PTS Millenia Sdn. Bhd., 2010), 142.

13 'Abd al-Maj̄ì al-Zindānī, Keajaiban Puasa Mukjizat dan Pembuktian Saintifik, terj. Adli Mohd Saad dan Tazlie Sham Abdul Rahman; Petaling Jaya: Wahyu Suci Sdn. Bhd., 2010), 21. 
bahawa puasa membantu menurunkan berat badan mereka. ${ }^{14}$ Natijahnya, pembuangan toksin dan lemak berlebihan akan meningkatkan tahap kesihatan dan kecerdasan orang yang berpuasa.

2. Perseimbangan antara rukhșah dan pencapaian maqāṣid puasa.

Allah SWT telah memperuntukkan jalan keluar bagi pesakit yang tidak mampu meneruskan puasa dengan keizinan berbuka puasa dan menggantikannya pada hari yang lain. Namun, sakit adalah bersifat subjektif, sakit semata-mata tidak boleh dijadikan sebab untuk mendapatkan rukhșah. Pengamalan rukhșah perlu merujuk kepada hikmah rukhṣah itu sendiri iaitu untuk mengelakkan kemudaratan kepada orang yang berpuasa. Oleh itu, selagimana pesakit tidak mendapat kemudaratan dengan berpuasa, mereka digalakkan untuk meneruskan puasa demi menggarap pahala dan kebaikan-kebaikan lain bagi puasa Ramadan. ${ }^{15}$ Selain daripada itu, sakit juga bersifat relatif, iaitu tahap kesakitan berbeza menurut individu. Ada individu yang boleh menahan kesakitan yang banyak, ada pula individu yang tidak boleh menahan kesakitan walaupun ianya adalah kesakitan yang ringan bagi individu yang lain. Oleh itu, pengamalan rukhșah secara mutlak adalah bertentangan dengan kemaslahatan pesakit itu sendiri. Pandangan sains juga turut membezakan antara sakit dan penyakit. Ada sesetengah pesakit yang menghidap penyakit secara berterusan seperti darah tinggi, asma dan sebagainya tetapi tidak mengalami kesakitan sepanjang masa. Sakit lebih merujuk kepada simptom yang berlaku seperti orang yang berpenyakit darah tinggi menghadapi sakit pada bahagian kepala atau leher. Dengan itu, rukhșah berbuka puasa hanya diberikan kepada orang yang menghadapi simptom daripada penyakit yang dihadapinya. Kesimpulannya, berdasarkan perbincangan fuqaha dan pandangan sains perubatan, sakit yang dianggap

14 American Journal of Applied Sciences 4, no. 8, Science Publications (2007): 565-569.

15 Ibn Qudāmah, Muwaffaq al-Dīn Abū Muhammad 'Abd Allah bin Aḥmad bin Muḥammad, al-Mughnī, ed. ke-4 (al-Qāhirah: Hijr li alȚibā'ah, 1992), 4:403. 
sebagai rukhṣah berbuka puasa dan menggantikannya pada hari yang lain ialah seperti berikut:

a. Sakit yang mempunyai harapan untuk sembuh. Oleh itu, orang yang menghidap sakit yang tidak mempunyai harapan untuk sembuh tidak perlu berpuasa, mereka boleh menggantikan puasa mereka dengan membayar fidyah.

b. Sakit yang menyebabkan pesakit tidak mampu untuk berpuasa sama ada dari segi fizikal atau mental.

c. Sakit yang memudaratkan pesakit sekiranya meneruskan puasa. Kemudaratan yang timbul sama ada menambahkan lagi kesakitan atau melambatkan proses penyembuhan.

d. Puasa menghalang pesakit daripada mendapat rawatan seperti memakan ubat dan sebagainya. Bagi pesakit seperti ini, mereka boleh berbuka puasa dan menggantikannya pada hari yang lain.

e. Orang yang sihat tetapi bimbang akan sakit sekiranya berpuasa.

f. Orang yang terlalu lapar dan terlalu dahaga juga dikategorikan sebagai orang sakit menurut Ibn Qudāmah. ${ }^{16}$

Kesimpulannya, bagi pesakit yang mempunyai penyakit tetapi tidak mengalami simptom penyakit tersebut, ataupun mengalami simptom pada kadar yang minima dan tidak memudaratkan diri, mereka digalakkan untuk berpuasa demi mendapatkan kelebihan puasa Ramadan yang amat besar. Bagi pesakit yang perlu menjalani rawatan dan mampu berpuasa, mereka perlu merujuk kepada pegawai perubatan untuk menyesuaikan kaedah rawatan seperti menyesuaikan waktu pengambilan ubat dengan waktu puasa, menggunakan kaedah pengambilan ubat yang tidak membatalkan puasa, mengubah waktu rawatan yang sesuai dengan waktu puasa sekiranya boleh. Oleh itu, penentuan kesan kaedah rawatan terhadap kesahihan puasa pesakit perlu diteliti dan dikaji dengan mengambilkira peruntukan rukhșah kepada pesakit dan pencapaian objektif-

16 Ibn Qudāmah, al-Kāfí fì Fiqh al-Imām Ahmad bin Hanbal (Bayrūt: Dār al-Kutub al-'Ilmiyyah, 2001), 1:451. 
objektif di sebalik pensyariatan ibadah puasa itu sendiri. Justeru, hukum-hukum yang dikeluarkan akan memberikan maslahah yang optimum kepada pesakit keseluruhannya.

3. Rujukan kepada dalil-dalil yang sahih dan pengertian al-jawf yang sebenar.

Penelitian kepada dalil-dalil berkaitan puasa menunjukkan bahawa dalil-dalil yang menerangkan tentang perkara-perkara yang membatalkan puasa adalah terhad. Keterbatasan dalil-dalil ini bukanlah satu kekurangan bagi syariat tetapi merupakan satu cabaran bagi para fuqaha untuk menilai isu-isu terbaru berkaitan puasa berdasarkan prinsip-prinsip umum sedia ada. Aspek ketajaman akal yang didasari prinsip-prinsip Islam yang asas tidak dinafikan dalam pembentukan hukum-hukum Islam. ${ }^{17}$ Oleh itu, penemuan sains perubatan mempunyai peranan yang signifikan dalam membantu fuqaha memahami struktur anggota badan demi mendapatkan gambaran yang jelas mengenai al-jawf yang menjadi mihwwar utama perbincangan perkaraperkara yang membatalkan puasa. Penemuan sains perubatan juga dapat membantu fuqaha mendapatkan gambaran yang lebih jelas mengenai mekanisme sesuatu kaedah rawatan yang dijalankan ke atas pesakit. Jalinan antara dalil-dalil yang sahih dan pandangan sains perubatan dapat menghasilkan pengertian al-jawf yang lebih komprehensif dan tepat. Pemahaman mengenai pengertian al-jawf yang sebenar amat penting dalam menilai kesan kaedah-kaedah rawatan perubatan ke atas puasa pesakit kerana kebanyakan kaedah rawatan perubatan melibatkan proses memasukkan sesuatu ubat atau objek ke dalam bahagian-bahagian badan pesakit. Justeru, pemahaman tentang pengertian al-jawf yang samar sudah tentu akan menatijahkan hukum yang tidak tepat dan jauh dari kehendak sebenar syarak.

Berdasarkan dalil-dalil sahih dan perbahasan fuqaha silam dan kontemporari, perkara-perkara yang membatalkan puasa adalah seperti berikut:

Mahmood Zuhdi Abdul Majid, Sejarah Pembinaan Hukum Islam (Kuala Lumpur: Jabatan Penerbitan Universiti Malaya,1996), 95. 
a. Makan dan minum.

Makan dan minum dianggap sebagai perkara utama yang membatalkan puasa kerana keduanya bertentangan dengan maksud puasa iaitu menahan diri dari makan dan minum kerana Allah SWT. Hukum ini telah disepakati oleh para fuqaha. ${ }^{18}$ Makan dan minum yang dianggap sebagai pembatal puasa ialah seperti berikut:

1. Makan atau minum dengan menggunakan cara biasa iaitu melalui mulut, sampai ke perut melalui kerongkong. Makanan yang tidak sampai ke kerongkong tidak dikira sebagai makan yang membatalkan puasa. Dalilnya ialah qiyas kepada kebenaran berkumur-kumur bagi orang yang berpuasa. ${ }^{19}$

2. Subjek makanan tidak terhad kepada makanan dan ubatubatan sahaja, malah boleh merangkumi bahan-bahan selain makanan sama ada bermanfaat atau tidak. Oleh itu sekiranya seseorang yang berpuasa makan bahan-bahan yang bukan berunsur makanan seperti batu atau bahanbahan yang membahayakan seperti racun, puasanya akan batal. Termasuk dalam bahan yang membatalkan puasa ialah bahan-bahan yang berunsur kesukaan atau keinginan seseorang seperti syisya, rokok, dadah dan sebagainya. ${ }^{20}$

3. Tidak ada had minima bagi makanan yang dimakan sebagaimana fuqaha tidak meletakkan syarat kenyang sebagai pembatal puasa. Ini adalah kerana mengenyangkan bersifat subjektif. Kekenyangan berbeza dari individu dengan individu yang lain walaupun diukur pada makanan yang sama. Oleh kerana itu, jumhur fuqaha berpendapat bahawa makan atau minum walaupun sedikit seperti (sekadar sebiji bijan) dianggap membatalkan puasa. ${ }^{21}$

Al-Nawawī, al-Majmū', 4:334.

19 Ibn Rushd al-Qurțub̄̄ al-Andalūs̄̄, Abū al-Walid Muhammad bin Aḥmad bin Muḥammad bin Aḥmad, Bidāyah al-Mujtahid wa Nihāyah al-Muqtaṣid (Bayrūt: Dār al-Kutub al-'Ilmiyyah, 1996), 3:162.

20 Ibn Qudāmah, al-Mughnī, 4:350.

21 Al-Nawawī, al-Majm̄̄', 6:341. 
b. Jimak

Berdasarkan dalil dari al-Quran, ${ }^{22}$ jimak merupakan pembatal puasa yang disepakati oleh para fuqaha. Ini adalah kerana jimak bertentangan dengan maksud puasa itu sendiri iaitu menahan diri dari kehendak syahwat dan nafsu seks sebagai proses pengabdian kepada Allah SWT. Oleh itu, melakukan hubungan seks dengan apa kaedah sekalipun adalah dilarang semasa berpuasa kerana ianya bertentangan dengan objektif puasa yang telah disebutkan.

c. Memasukkan sesuatu ke dalam al-jawf

Memasukkan sesuatu ke dalam al-jawf juga merupakan perkara yang membatalkan puasa yang disepakati oleh fuqaha. ${ }^{23}$ Hadis yang menjadi sandaran para fuqaha ialah hadis yang diriwayatkan oleh Laqīṭ bin Șabrah iaitu:

$$
\begin{aligned}
& \text { عن لقيط بن صبرة قال: قال رسول الله صلى الله عليه وسلم: بالغ } \\
& \text { في الاستنشاق إلا أن تكون صائما.24 فئن }
\end{aligned}
$$

Maksudnya: Daripada Laqìt bin Sabrah berkata, Rasulullah SAW telah bersabda: "Masukkanlah air ke dalam hidung secara berlebihan (ketika wuduk) kecuali sekiranya kamu sedang berpuasa".

Hadis tersebut menerangkan bahawa orang yang berpuasa tidak dibenarkan untuk berlebih-lebihan memasukkan air ke dalam hidung ketika berwuduk. Larangan ini bertujuan mengelakkan air daripada memasuki bahagian dalam hidung dan seterusnya memasuki al-jawf. Fuqaha silam berpendapat bahawa al-jawf yang dimaksudkan di dalam hadis ini ialah otak dan perut. Pentafsiran ini didorong oleh konotasi perkataan aljawf dari sudut bahasa yang merujuk kepada perut dan otak. Berdasarkan pemahaman ini, fuqaha berpandangan bahawa larangan memasukkan air secara berlebihan ke dalam hidung

Surah al-Baqarah (2): 187

Al-Nawawī, al-Majmū', 6:333.

Abū Dāwūd Sulaymān bin al-Ash'ath al-Sajastān̄i, Sunan Ab̄̄ Dāwūd, Kitāb al-Wuḍū', Bāb fī al-Istinthār, no. hadith 2366 (Bayrūt: Dār al-Kutub al-'Ilmiyyah, 1996). 
bertujuan mengelakkan air dari masuk ke dalam otak yang dianggap sebagai al-jawf. ${ }^{25}$ Walau bagaimanapun, alasan yang tepat kepada larangan tersebut ialah untuk mengelakkan air dari sampai ke kerongkong melalui hidung kerana air yang sampai ke kerongkong akan membatalkan puasa. Seterusnya, fuqaha silam juga turut menganggap bahawa semua bukaan semulajadi dan bukan semulajadi sebagai al-jawf. Antara bukaan-bukaan semulajadi tersebut ialah mulut, mata, hidung, mata, telinga, faraj, salur kencing dan dubur. Manakala bukaan bukan semulajadi pula ialah seperti luka, bekam dan suntikan (الحقنة). ${ }^{26}$

Fuqaha silam didapati tidak bersepakat ke atas bahagianbahagian badan yang dianggap sebagai al-jawf. Selain dari hadis Laqịt yang menjadi asas perbincangan, pendapat para fuqaha mengenai bahagian-bahagian badan yang dianggap sebagai aljawf adalah bersifat ijtihādī. Namun, kerangka perbincangan mereka mengenai al-jawf menggambarkan bahawa maksud al-jawf ialah bahagian-bahagian dalam badan yang berfungsi memproses dan menyerap zat-zat dari makanan dan minuman. Setelah merujuk kepada pandangan sains perubatan, bahagianbahagian badan yang berkait secara langsung dalam proses penghadaman ialah mulut, kerongkong, perut, usus kecil dan usus besar. Walau bagaimanapun, mulut tidak dianggap sebagai al-jawf kerana terdapat dalil yang mengharuskan berkumurkumur dan merasa makanan dengan lidah semasa berpuasa. ${ }^{27}$ Dengan itu, al-jawf ialah sebahagian daripada anggota sistem penghadaman iaitu kerongkong, perut, usus kecil dan usus besar. Manakala bukaan bukan semulajadi yang dianggap sebagai al-jawf ialah bukaan pada bahagian-bahagian yang telah terbukti adalah sebahagian dari al-jawf, iaitu bukaan pada kerongkong, perut, usus kecil, usus besar, hidung dan bahagian dalam telinga.

25 Al-Nawawī, al-Majmū', 6:335.

26 Ibn Rushd, Bidāyah al-Mujtahid, 2:703.

27 'Abd al-Ḥalīm 'Abd al-Ḥāiz Khālid 'Aqrab, "Aḥkām al-Ṣiyām al-Mutarattibah "alā Taḥdīd al-Jawf" (Master Thesis University of Yarmouk, Jordan, 2005), 48. 
Sebagai kesimpulan, perbuatan memasukkan sesuatu ke dalam al-jawf akan dianggap membatalkan puasa sekiranya memenuhi salah satu dari ciri-ciri berikut:

a. Mengandungi makna dan bentuk perbuatan makan atau minum seperti memasukkan sesuatu berunsur makanan melalui jalan yang biasa iaitu mulut dan kerongkong. Contohnya makan makanan atau minum cecair melalui mulut dan sampai ke dalam perut melalui kerongkong.

b. Mengandungi bentuk perbuatan makan iaitu memasukkan sesuatu ke dalam al-jawf melalui mulut walaupun objek tersebut bukan berunsur makanan. Contohnya makan ubat melalui mulut, memasukkan alat seperti tiub makanan atau ubat melalui kerongkong.

c. Mengandungi makna makan iaitu memasukkan sesuatu berunsur makanan melalui jalan-jalan atau bukaan bukan biasa ke dalam al-jawf. Contohnya pemberian makan melalui tiub kepada pesakit.

Dengan itu, kesan rawatan secara suntikan terhadap hukum puasa akan didasarkan kepada perkara-perkara yang membatalkan puasa yang telah disepakati oleh majoriti fuqaha iaitu makan, minum, jimak dan memasukkan sesuatu ke dalam al-jawf.

\section{MEKANISME PEMBERIAN UBAT MELALUI SUNTIKAN}

Memasukkan ubat secara suntikan ke dalam badan mempunyai beberapa cara iaitu secara suntikan ke dalam vena (intravenously), suntikan ke bawah kulit (subcutaneously), suntikan ke dalam otot (intramuscularly), dan tulang belakang (intrathecal). Suntikan ke dalam vena menentukan ubat memasuki salur darah secara langsung. Suntikan yang dilakukan akan menyampaikan ubat terus ke pembuluh darah atau salur darah vena. Melalui cara ini, ubat tidak perlu diserap daripada usus. Oleh yang demikian kaedah ini akan memberikan kesan yang lebih pantas berbanding pengambilan ubat secara oral. Kaedah ini digunakan bagi pesakit 
yang mempunyai halangan untuk menelan ubat atau mengalami masalah penyerapan ubat melalui dinding usus oleh kerana penyakit tertentu. Suntikan intravena juga digunakan untuk menyalurkan cecair bernutrien bagi pesakit yang mengalami kesukaran untuk mengambil makanan melalui jalan biasa. ${ }^{28}$

Bagi cara suntikan ke bawah kulit, jarum akan dimasukkan ke dalam tisu lemak yang terdapat di bawah permukaan kulit. Ubat yang disuntik kemudian akan bergerak ke dalam kapilari darah melalui lymphatic vessel. Cara suntikan ini sesuai untuk ubat yang bersifat protien tinggi seperti insulin kerana ubat seperti ini akan dihadam di dalam sistem penghadaman sekiranya diambil secara oral. Insulin memudahkan pengangkutan glukosa dan asid amino menyeberangi selaput sel iaitu menambahkan pengambilan glukosa oleh sel-sel. Proses ini akan menurunkan paras glukosa di dalam darah dan menambah penggunaan glukosa di tisu-tisu, serta menghalang pengeluaran glukosa dari glikogen dalam hati dan otot. ${ }^{29}$

Bagi cara suntikan ke dalam otot, jarum yang lebih besar digunakan untuk memasukkan ubat ke dalam otot yang terdapat di bawah tisu lemak. Biasanya suntikan ke dalam otot digunakan untuk memasukkan ubat dalam kuantiti yang lebih banyak. Suntikan pada otot akan diberikan pada bahagian lengan atas, paha atau punggung. Ubat yang disuntik kemudiannya akan bergerak daripada otot ke tempat yang sakit melalui kapilari darah. Kecepatan ubat bertindak bergantung kepada darah yang dibekalkan ke otot tersebut. Bekalan darah ke otot akan meningkat dengan penggunaan otot tersebut. ${ }^{30}$

Cara suntikan yang terakhir ialah melalui tulang belakang. Ubat akan disuntik dengan jarum yang dimasukkan di antara dua vertebrae pada bahagian bawah tulang belakang dan ke dalam ruang sekeliling tulang belakang.Ubat kemudian disuntik ke dalam spinal canal. Sebelum melakukan suntikan, pesakit akan diberikan pelali setempat pada bahagian yang akan disuntik. Kaedah suntikan

28 Shiela A. Sorrentino, Mosby's Textbook for nursing Assistant, ed. ke-6 (USA: Mosby, 1984), 448.

29 Lim Yeok Siew, Farmakologi Asas (Kuala Lumpur: Dewan Bahasa dan Pustaka, 1989), 100.

30 Lim Yeok Siew, Farmakologi Asas, 100. 
ini biasanya dilakukan untuk menghasilkan kesan yang cepat dan setepat pada otak, saraf tunjang dan lapisan yang menutupi otak (meningis). Contoh cara suntikan ini ialah suntikan epidural untuk mengurangkan sakit ketika bersalin. Bahan yang diambil melalui kaedah suntikan adalah dalam bentuk cecair. Ubatan yang disuntik terdapat dalam beberapa sifat iaitu ubat untuk rawatan penyakit, vitamin untuk kesihatan dan bahan yang bersifat makanan yang diberikan kepada pesakit seperti glukos. Kesan suntikan ke atas puasa pesakit berbeza menurut bahan yang disuntik. ${ }^{31}$

\section{KESAN PEMBERIAN UBAT MELALUI SUNTIKAN KEPADA HUKUM PUASA PESAKIT}

Fuqaha silam berpendapat bahawa suntikan ke dalam badan membatalkan puasa. Mereka telah mengqiyaskan suntikan kepada perbuatan memasukkan air ke dalam hidung secara berlebih-lebihan ketika berpuasa. Mereka berpandangan bahawa larangan tersebut bertujuan mengelakkan daripada air naik ke otak yang dianggap sebagai sebahagian dari al-jawf. ${ }^{32}$ Selain daripada itu, al-Nawawī turut menukilkan pendapat-pendapat fuqaha yang berpandangan sebaliknya. Sebagai contoh, al-Qāḍī Husayn berpendapat bahawa suntikan tidak membatalkan puasa, namun pendapat ini tidak popular dan amat asing pada ketika itu. ${ }^{33}$ Pendapat yang terpencil ini kemudiannya dipopularkan oleh fuqaha terkemudian seperti Ibn Taymiyyah yang berpendapat bahawa suntikan tidak membatalkan puasa. Menurut beliau, qiyas yang menjadi hujah fuqaha silam masih terdedah kepada kritikan. Alasannya, suntikan dan perbuatan memasukkan air ke dalam hidung adalah dua perkara yang berbeza. Air yang sampai ke dalam hidung tidak akan sampai ke otak, malah akan turun ke dalam perut melalui kerongkong. Jadi, proses ini adalah mirip kepada perbuatan minum yang jelas membatalkan puasa. Oleh itu, suntikan dan memasukkan air melalui hidung adalah dua perkara yang berbeza dan menggunakan qiyas untuk menyamakan

\footnotetext{
31 Lim Yeok Siew, Farmakologi Asas, 100.

32 Al-Nawawī, al-Majmū', 6:334.

33 Al-Nawawī, al-Majmū', 6:335.
} 
antara kedua-dua perbuatan tersebut adalah 'qiyās ma'al-färiq' (perbandingan yang tidak tepat). ${ }^{34}$

Ibn Taymiyyah juga turut menekankan bahawa perkaraperkara berkaitan pelaksanaan ibadah puasa mestilah merujuk kepada dalil-dalil yang sahih dan memahami objektif puasa itu sendiri. Ini adalah kerana puasa merupakan ibadah yang asasi dalam Islam. Walau bagaimanapun, tidak ada satu riwayat yang sahih yang menjelaskan tentang beberapa perkara yang dianggap membatalkan puasa oleh para fuqaha silam seperti suntikan, merawat luka yang serius pada kepala dan perut. Sedangkan perkara-perkara tersebut sering dialami oleh para sahabat dalam kehidupan harian mereka terutamanya semasa peperangan. Oleh itu, selain daripada melihat kepada dalil-dalil yang berkaitan, penilaian sesuatu perbuatan yang memberikan kesan kepada kesahihan puasa sewajarnya dikaitkan dengan objektif puasa itu sendiri, iaitu tujuan sebenar larangan makan dan minum ialah wujudnya unsur ketaatan dan nilai taqwa yang ingin dicapai. Ini kerana ketaatan seorang hamba untuk meninggalkan perkara yang menjadi keinginannya merupakan satu pengorbanan yang akan menjana taqwa di sisi Allah. Ketaqwaan yang dipupuk melalui perbuatan menahan nafsu demi melaksanakan ibadah puasa pula tidaklah terjejas kerana suntikan yang lazimnya adalah untuk tujuan perubatan dan bukannya memenuhi tuntutan nafsu. ${ }^{35}$

Natijahnya, pandangan ini lebih menjadi pilihan kebanyakan fuqaha kontemporari apabila mereka turut berpandangan bahawa suntikan tidak membatalkan puasa. Malah terdapat sebahagian dari mereka seperti al-Qaraḍāwī telah mengharuskan suntikan secara mutlak sama ada suntikan ubat atau cecair bernutrien. ${ }^{36}$ Atas alasan yang sama, mereka berpendapat bahawa suntikan ubat dan vitamin seperti $\mathrm{C}$ dan $\mathrm{K}$ juga tidak membatalkan puasa. Alasan yang dikemukakan oleh mereka ialah, perbuatan suntikan tidak boleh disamakan dengan perbuatan makan atau minum yang

34 Ibn Taymiyyah al-Harrānī, Taqiy al-Dīn Abū al-'Abbās Aḥmad Ibn 'Abd al-Halīm Ibn 'Abd al-Salām, Majmū'ah al-Fatāwā (alManșūrah: Dār al-Wafā', 1998), 25:126.

35 Ibn Taymiyyah, Majmū'ah al-Fatāwā, 25:126.

36 Yūsuf al-Qaraḍāwī, Fiqh al-Ṣiyām (al-Qāhirah: Maktabah Wahbah, 2006), 86. 
membatalkan puasa kerana pesakit tidak akan berasa kenyang. ${ }^{37}$ Malah apa yang dirasai oleh pesakit hanyalah kecergasan dan pertambahan tenaga sebagaimana yang berlaku sekiranya mereka mandi atau membasuh anggota badan. Menurut pandangan perubatan juga, pesakit yang menerima suntikan cecair sama ada berunsur gula atau garam tidak akan berasa kenyang, tetapi mereka hanya akan rasa bertenaga dan tidak lapar kerana lapar ialah tindakbalas badan apabila zat tidak mencukupi. ${ }^{38}$ Walaupun al-Qaraḍāwī berpendapat bahawa suntikan cecair yang berunsur makanan tidak membatalkan puasa, namun beliau mencadangkan agar pesakit yang menerima suntikan bendalir bernutrien untuk mengambil rukhsah berbuka puasa dan menggantikannya pada hari yang lain kerana biasanya pesakit yang mendapat suntikan sebegini adalah pesakit yang mencapai tahap sakit yang berhak mendapat rukhșah berbuka puasa dan menggantikannya pada hari yang lain. ${ }^{39}$ Pandangan ini diperakui oleh pegawai-pegawai perubatan yang mencadangkan agar pesakit yang menerima suntikan bernutrien untuk berbuka puasa atas alasan keadaan yang menyebabkan pesakit diberi suntikan bernutrien adalah pesakit yang menghadapi sakit yang berat. ${ }^{40}$

Berdasarkan perbahasan fuqaha silam dan kontemporari, pengkaji lebih cenderung untuk membezakan antara suntikan ubat dan suntikan cecair bernutrien. Ini adalah kerana suntikan cecair

37 Pendapat ini bersandarkan kepada teori bahawa puasa ialah ibadah ghayr ma'qūlah ma'nā (tidak berasaskan logik akal) iaitu yang menatijahkan perkara-perkara yang membatalkan puasa hanya terhad kepada makan dan minum melalui jalan biasa sahaja. Manakala pendapat yang mengatakan puasa tidak batal dengan suntikan bendalir bernutrien adalah berdasarkan teori bahawa puasa ialah ibādah ma'qūlah ma' 'nā (berasaskan logik akal) yang menatijahkan perkara-perkara yang membatalkan puasa tidak terhad kepada perbuatan makan dan minum melalui jalan biasa sahaja. Lihat: Majallah Majma' al-Fiqh al-Islāmī, (Jeddah: Muktamar Majlis Majma‘ al-Fiqh al-Islāmī, bil. 10, 1997) ii. 320.

38 Temubual dengan Mona Mohd Rosli, Jururawat di Hospital alZahraa, Bangi. 23 Disember 2011.

39 Yūsuf al-Qaraḍāwī, Fiqh al-Siyām, 86.

40 Temubual dengan Prof. Madya Dr. Harlina Siraj, Pakar Perunding Obstetriks \& Ginekologi Hospital Universiti Kebangsaan Malaysia, April 2012. 
bernutrien seperti glukos (dextose), garam (saline) dan sebagainya adalah mirip kepada perbuatan makan dan minum pada maknanya, iaitu memasukkan makanan atau minuman ke dalam badan melalui cara bukan biasa iaitu mulut dan kerongkong, yang mana badan akan mendapat manfaat dari cecair tersebut. Oleh itu, suntikan cecair bernutrien dianggap membatalkan puasa. Manakala suntikan ubat tidak membatalkan puasa kerana tidak mempunyai gambaran atau makna makan atau minum yang membatalkan puasa.

\section{KESIMPULAN}

Sebagai kesimpulan, kaedah rawatan melalui suntikan merupakan antara kaedah rawatan yang berkesan kepada pesakit. Rawatan suntikan boleh dilakukan mengikut keperluan dengan cara-cara berikut, iaitu suntikan ke dalam vena (intravenously), suntikan ke bawah kulit (subcutaneously), suntikan ke dalam otot (intramuscularly), dan tulang belakang (intrathecal). Suntikan yang diberikan boleh berbentuk ubat, vitamin atau cecair bernutrien.

Setelah meneliti dalil-dalil berkaitan serta pandangan fuqaha silam dan kontemporari, kajian ini mendapati bahawa kaedah rawatan suntikan melalui semua cara tidak membatalkan puasa. Walau bagaimanapun, suntikan cecair bernutrien dianggap membatalkan puasa kerana mempunyai makna makan, iaitu memasukkan makanan ke dalam badan melalui jalan lain selain kerongkong.

Dengan itu, penilaian sesuatu perkara mengenai kesannya ke atas hukum puasa perlu didasarkan kepada beberapa prinsip asas iaitu pertama, memahami maqāșid puasa dalam kerangka maqāṣid sharī'ah; kedua, perseimbangan antara rukhșah dan pencapaian maqāșid puasa; ketiga, merujuk kepada dalil-dalil yang sahih. 


\section{BIBLIOGRAFI}

'Abd al-Ḥalīm 'Abd al-Ḥāiz Khālid 'Aqrab. "Ahkām al-Ṣiyām al-Mutarattibah 'alā Tahdīd al-Jawf'. Master Thesis University of Yarmouk, Jordan, 2005.

Agus Mustafa. Puasa Terapi dalam Ibadah. Batu Caves: PTS Millenia Sdn. Bhd., 2010.

Al-Nawawī, Abū Zakariyyā Maḥy al-Dīn bin Sharaf. Kitāb alMajmū' Sharh al-Muhadhdhab li al-Shīrāzī. Jil. 6. Bayrūt: Dār Iḥyā’ al-Turāth al-'Arabī, 1995.

Al-Qaraḍāwī, Yūsuf. Fiqh al-Ṣiyām. Al-Qāhirah: Maktabah Wahbah, 2006.

Al-Qurțubī, Abū 'Abd Allah Muḥammad bin Aḥmad al-Anșārī. Al-Jāmi ' li Ahkām al-Qur'ān. Bayrūt: Dār Ihyyā' al-Turāth al-'Arabī, 1995.

Al-Rāzī, Fakhr al-Dīn Muhammad bin 'Umar bin al-Husayn bin al-Hasan bin 'Alī al-Tamīmī al-Bakrī. Al-Tafsìr al-Kabìr. Bayrūt: Dār al-Kutub al-'Ilmiyyah, 1990.

Al-Sajastānī, Abū Dāwūd Sulaymān bin al-Ash'ath. Sunan Abì Dāwūd. Bayrūt: Dār al-Kutub al-'Ilmiyyah, 1996.

Al-Zindānī, 'Abd al-Mājid. Keajaiban Puasa Mukjizat dan pembuktian saintifik. Terj. Adli Mohd Saad dan Tazlie Sham Abdul Rahman. Petaling Jaya: Wahyu Suci Sdn. Bhd., 2010 .

Al-Zuhaylī, Wahbah. Ușūl al-Fiqh al-Islāmī. Bayrūt: Dār al-Fikr al-Mu'āṣir, 1986.

American Journal of Applied Sciences 4. No. 8. Science Publications, (2007).

Fath al-Duraynī. Dirāsāt wa Buhūth fì al-Fikr al-Islāmīal-Mu' 'ạṣir. Damshiq: Dār Qutaybah, 1998.

Harlina Siraj. Pakar Perunding Obstetriks \& Ginekologi Hospital Universiti Kebangsaan Malaysia. 
Husayn Ḥāmid Ḥasan. Naẓariyyah al-Maṣlaḥah fì al-Fiqh alIslāmī. Al-Qāhirah: Maktabah al-Mutanabbī, 1981.

Ibn Qudāmah, Muwaffaq al-Dīn Abū Muhammad 'Abd Allah bin Aḥmad bin Muhammad. Al-Käfífí Fiqh al-Imām Ahmad bin Hanbal. Jil. 1. Bayrūt: Dār al-Kutub al-'Ilmiyyah, 2001.

Ibn Qudāmah, Muwaffaq al-Dīn Abū Muhammad 'Abd Allah bin Aḥmad bin Muḥammad. Al-Mughnī. Ed. ke-4. Al-Qāhirah: Hijr li al-Ṭibā'ah, 1992.

Ibn Rushd al-Qurțubī al-Andalūsī, Abū al-Wālid Muhammad bin Aḥmad bin Muḥammad bin Aḥmad. Bidāyah al-Mujtahid wa Nihāyah al-Muqtașid. Bayrūt: Dār al-Kutub al-'Ilmiyyah, 1996.

Ibn Taymiyyah al-Ḥarrān̄̄, Taqiy al-Dīn Abū al-'Abbās Aḥmad Ibn 'Abd al-Halīm Ibn 'Abd al-Salām. Majmū'ah al-Fatāwā. al-Manșūrah: Dār al-Wafā', 1998.

Ibrāhīm Anīs et al. Al-Mu 'jam al-Wasìṭ. Al-Qāhirah: t. p., 1392.

Lim Yeok Siew. Farmakologi Asas. Kuala Lumpur: Dewan Bahasa dan Pustaka, 1989.

Mahmood Zuhdi Abdul Majid. Sejarah Pembinaan Hukum Islam. Kuala Lumpur: Jabatan Penerbitan Universiti Malaya, 1996.

Majallah Majma' al-Fiqh al-Islāmī. Jeddah: Muktamar Majlis Majma’ al-Fiqh al-Islāmī. Bil. 10, 1997, ii.

Mona Mohd Rosli, Jururawat di Hospital al-Zahraa, Bangi.

Shiela A. Sorrentino, Mosby's Textbook for Nursing Assistant. Ed. ke-6. USA : Mosby, 1984.

SENARAI RUJUKAN LAMAN WEB

http://qurancomplex.com.

http://www.islam-usa.com/. 
Jurnal Fiqh, No. 9 (2012) 65-86 